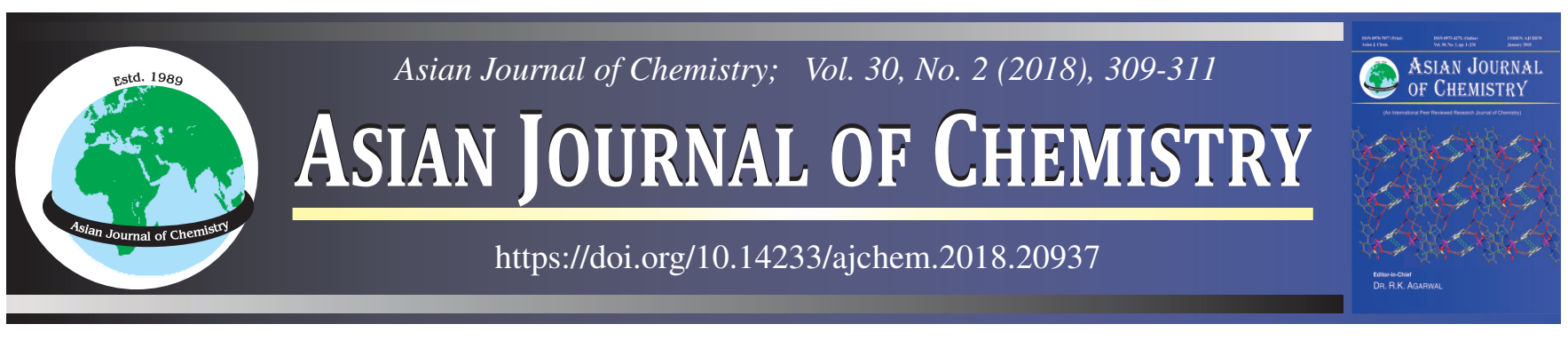

\title{
Mild and Versatile Potassium Fluoride/Tetrabutylammonium Fluoride Protocol for Ester Hydrolysis
}

\author{
D. Vijayalakshmi, K. Balakrishna and Shaik Mustafa*
}

Department of Chemistry, GITAM Deemed to be University, Hyderabad Campus, Rudaram, Sangareddy-502 329, India

*Corresponding author: E-mail: mustaff_02@yahoo.co.in

A mild and versatile protocol of potassium fluoride/tetrabutylammonium fluoride (KF/TBAF) in aqueous tetrahydrofuran for ester hydrolysis has been developed. The method is applied on variety of aliphatic and aromatic ester moieties bearing acid or base sensitive functional groups. The conditions have been also applied on acetates to yield alcohols. The chirality of optically pure esters remained intact with the conditions of the reaction.

Keywords: Carboxylic acids, Esters, Hydrolysis, Potassium fluoride, Tetrabutylammonium bromide.

\section{INTRODUCTION}

The functional group transformations play an important role to change the properties of the organic compounds and to utilize them for various applications from medical to material world. In the way, the success of the transformation is achieved when the other sensitive functional groups present in the substrates are unaffected. The hydrolysis of ester is an important conversion, which leads to variety of carboxylic acid derivatives. The carboxylic acid functional groups are found in many bioactive natural and synthetic organic compounds. Generally this conversion is being accomplished either by acidic [1] or alkaline [2] reagents and the reaction mechanism is well studied theoretically $[3,4]$. The drawback of these reaction conditions are seen when the substrates are holding other sensitive functional groups. In this view, various methods were developed for the ester hydrolysis viz., solid acids (e.g. zirconium phosphate), acidic ion-exchange resins (e.g. amberlite and zeolite) and even lipid-coated lipases [5]. Ishihara et al. [6] reported micelle-type $N, N$-diarylammonium pyrosulfate catalyst for the hydrolysis of various esters. But the reagents used by them are not easily available and expensive chemicals are needed for the preparation of the same.

The hydrolysis conditions reported in this communication are mild, high yielding and performed under neutral conditions with commercially available reagents. Further, the chiral centres of the optically pure esters are unaffected under the reaction conditions.

\section{EXPERIMENTAL}

Benzothiazolinone was purchased from Sigma-Aldrich. The solvents used in the synthesis were distilled before use. All other chemicals were of AR grade and were used without further purification. All melting points were obtained on Elico instrument, India (model MP96) and are uncorrected. NMR spectra were recorded on Bruker Top Spin Instrument. IR spectra were recorded using Bruker Alpha T OPUS instrument

Synthetic procedure for compound 4: To a solution of compound 3 (227 mg, $1 \mathrm{mmol}$ ) in DMF ( $5 \mathrm{~mL}$ ) was added $\mathrm{K}_{2} \mathrm{CO}_{3}$ (276 mg, $2.0 \mathrm{mmol}$ ) followed by ethyl bromo acetate (167 mg, $1.1 \mathrm{mmol}$ ) and the resultant suspension was stirred at room temperature for $16 \mathrm{~h}$. The reaction mixture was diluted with ethyl acetate $(40 \mathrm{~mL})$ and washed with water $(3 \times 30$ $\mathrm{mL}$ ). The organic layer was dried over $\mathrm{Na}_{2} \mathrm{SO}_{4}$ and evaporated under reduced pressure to afford a crude product which was triturated with hexane to give a off white coloured solid (300 mg, $0.96 \mathrm{mmol})$; m.p. $49-53{ }^{\circ} \mathrm{C}$; ${ }^{1} \mathrm{H} \mathrm{NMR}\left(\mathrm{CDCl}_{3}, 300 \mathrm{MHz}\right)$ : $\delta(\mathrm{ppm}) 7.29(\mathrm{~s}, 1 \mathrm{H}), 7.14(\mathrm{~d}, J=8.1 \mathrm{~Hz}, 1 \mathrm{H}), 6.83(\mathrm{~d}, J=8.1$ $\mathrm{Hz}, 1 \mathrm{H}), 4.66(\mathrm{~s}, 2 \mathrm{H}), 4.24(\mathrm{q}, J=7.2,2 \mathrm{H}), 3.52(\mathrm{t}, J=6.3$, $1 \mathrm{H}), 3.39$ (t, $J=6.3,1 \mathrm{H}), 2.81(\mathrm{t}, J=7.2 \mathrm{~Hz}, 2 \mathrm{H}), 2.22-2.01$ $(\mathrm{m}, 2 \mathrm{H}), 1.27(\mathrm{t}, J=7.2 \mathrm{~Hz}, 3 \mathrm{H}) ;{ }^{13} \mathrm{C} \mathrm{NMR}\left(\mathrm{CDCl}_{3}, 75 \mathrm{MHz}\right)$ : $\delta(\mathrm{ppm}): 167.1,162.9,136.5,135.1,126.9,122.8,122.6,110.3$, 62.2, 44.0, 43.6, 34.2, 32.3, 14.2; ESI-Ms $(M+1)=314$.

General procedure for ester and acetate hydrolysis: To a solution of ester or acetate $(1 \mathrm{mmol})$ in THF $(5 \mathrm{~mL})$ was added alkali metal fluoride $(2 \mathrm{mmol})$ followed by quaternary 
ammonium salt ( $1 \mathrm{M}$ in THF, $2 \mathrm{~mL}$ ) and the resultant solution was stirred for $7 \mathrm{~h}$. The reaction mixture was diluted with ethyl acetate $(30 \mathrm{~mL})$ and washed with water $(2 \times 20 \mathrm{~mL})$ followed by brine solution $(20 \mathrm{~mL})$. The organic layer was dried over $\mathrm{MgSO}_{4}$ and concentrated under reduced pressure to get a crude compound, which was triturated with hexane to get the corresponding product in 60-95 \% yield.

Compound 6: Off white solid, m.p. $166-169{ }^{\circ} \mathrm{C} ;{ }^{1} \mathrm{H}$ NMR $\left(\mathrm{CD}_{3} \mathrm{OD}, 300 \mathrm{MHz}\right): \delta(\mathrm{ppm}) 7.42(\mathrm{~s}, 1 \mathrm{H}), 7.22(\mathrm{~d}, J=7.8 \mathrm{~Hz}$, $1 \mathrm{H}), 6.83(\mathrm{~d}, J=7.8 \mathrm{~Hz}, 1 \mathrm{H}), 4.69(\mathrm{~s}, 2 \mathrm{H}), 3.54(\mathrm{t}, J=6.3,1 \mathrm{H})$, $2.81(\mathrm{t}, J=7.2 \mathrm{~Hz}, 2 \mathrm{H}), 2.12-2.02(\mathrm{~m}, 2 \mathrm{H}) ;{ }^{13} \mathrm{C} \mathrm{NMR}\left(\mathrm{CD}_{3} \mathrm{OD}\right.$, $75 \mathrm{MHz}): \delta$ (ppm): 172.2, 162.7, 136.6, 135.3, 126.5, 122.8, 122.3, 110.2, 45.9, 43.6, 32.1, 31.7; ESI-Ms $(M+1)=286$.

\section{RESULTS AND DISCUSSION}

The initial aim was to synthesize the fluoro compound $\mathbf{5}$ (Scheme-I) and to utilize the further modified derivatives for PET studies [6]. The chloro compound $\mathbf{3}$ was synthesized using a known procedure [7]. The same compound $\mathbf{3}$ was $\mathrm{N}$-alkylated with ethyl bromo acetate to form compound $\mathbf{4}$ which was confirmed by its ${ }^{1} \mathrm{H}$ NMR spectrum which showed the corresponding $\mathrm{N}-\mathrm{CH}_{2}$ peak at $\delta 4.6 \mathrm{ppm}$ as a singlet for two protons and the corresponding ester peaks at $\delta 4.25$ as a quartet for $-\mathrm{CH}_{2}$ and at $\delta 1.27$ as a triplet for $-\mathrm{CH}_{3}$ protons. When the fluorination reaction was performed on 4 using KF/TBAF in THF under refluxing conditions a more polar spot was observed on TLC. After completion of the reaction the compound was isolated and ${ }^{1} \mathrm{H}$ NMR spectrum of the same showed the absence of ethyl signals for the ester group. The $\mathrm{CH}_{2} \mathrm{Cl}$ peaks of $\mathbf{3}$ at 3.5 ppm were not disappeared in the spectrum, which indicated the presence of $\mathrm{CH}_{2} \mathrm{Cl}$ functionality as such under the reaction conditions. When the same reaction was performed for $15 \mathrm{~h}$, a mixture of chloro and fluoro acid compounds with 3 to 2 of respective ratio was observed.

The same conditions including 2 eq. of water were applied on various aliphatic and aromatic ester moieties (Table-1) and to the surprise the hydrolysis was observed in all the reactions and the carboxylic acids were formed about 70-95\% yield. Then the conditions were applied to de protect acetate group of phenol and 2-naphthol. The reaction was yielded free phenol and 2-naphthol in 62 and $64 \%$ yield, respectively. Further the conditions were applied on optically pure methyl(S)-mandelate of optical rotation $[\alpha]_{D}+144^{\circ},(c=1$ in methanol $)$ and on $N$-(tert-butoxycarbonyl)-L-phenylalanine methyl ester of optical rotation $[\alpha]_{D}-4^{\circ},(c=2$ in methanol). The two optically active esters afforded the corresponding carboxylic acids with the chirality unaffected. The isolated (S)-mandelic acid was

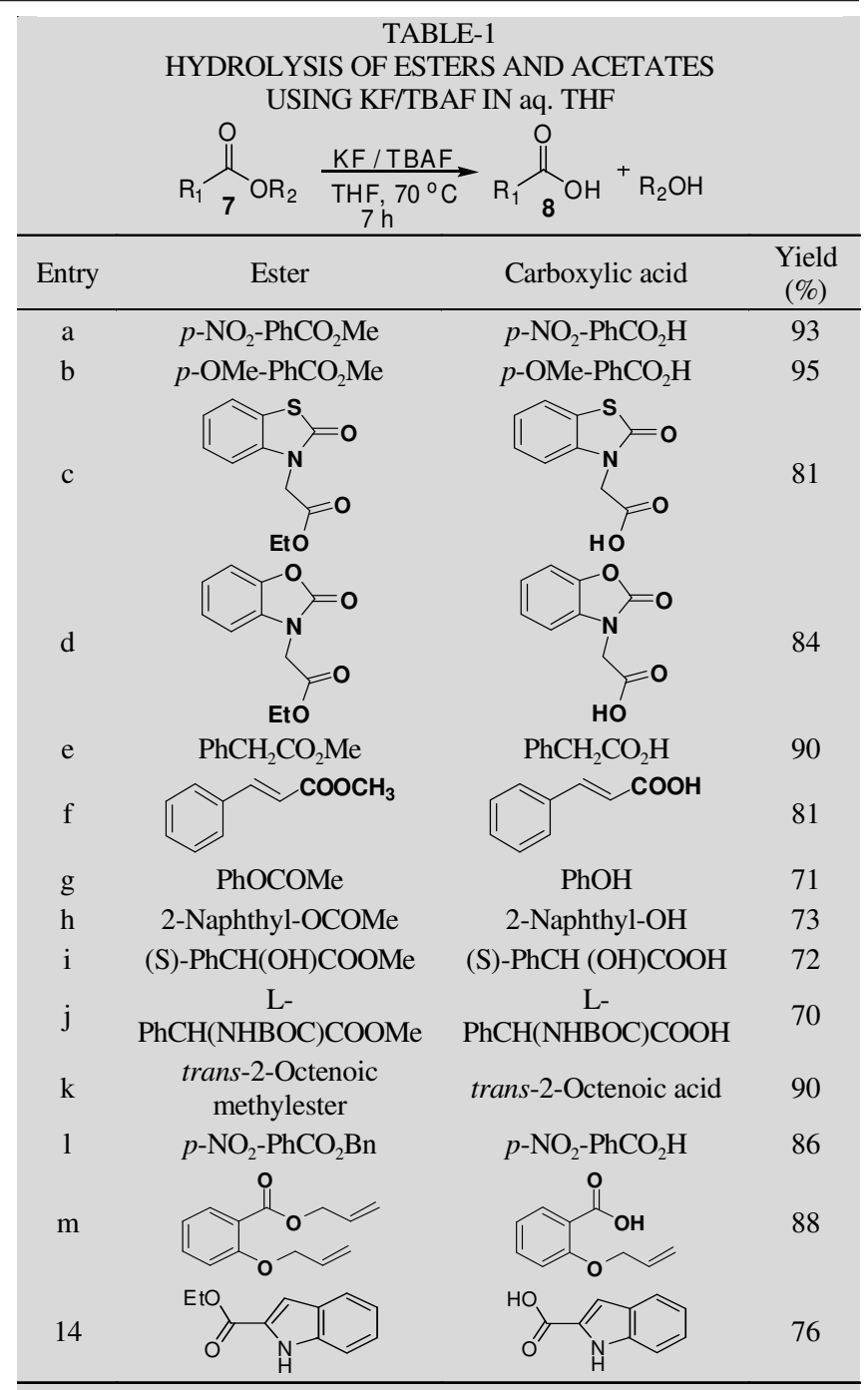

$\mathrm{Ph}=$ Phenyl, Reaction conditions: All the reactions were performed on $0.5 \mathrm{mmol}$ scale with 2 eq. potassium fluoride, 2 eq. of tetrabutylammonium fluoride, 2 eq. of $\mathrm{H}_{2} \mathrm{O}$ in $0.2 \mathrm{M} \mathrm{THF}$

shown optical rotation of $[\alpha]_{\mathrm{D}}+140^{\circ},(\mathrm{c}=2.0$ in water $)$ and that of $N$-(tert-butoxycarbonyl)-L-phenylalanine was shown $[\alpha]_{\mathrm{D}}$ $+25^{\circ},(\mathrm{c}=2.0$ in methanol). The esters $(\mathbf{7 a}, \mathbf{7 b}, \mathbf{7 e}, \mathbf{7 f}, \mathbf{7 g}, \mathbf{7 h}$, $\mathbf{7 i}, \mathbf{7 j}, \mathbf{7 k}$ and $\mathbf{7 l})$ and the carboxylic acids $(\mathbf{8 a}, \mathbf{8 b}, \mathbf{8 e}, \mathbf{8 f}, \mathbf{8 g}$, $\mathbf{8 h}, \mathbf{8 i}, \mathbf{8 j}$, 8k and $\mathbf{8 l}$ ) mentioned in the Table-1 are commercially known compounds and are confirmed by matching with the authentic compounds. The esters $\mathbf{7 c}, \mathbf{7 d}, \mathbf{7 m}, \mathbf{7 n}, \mathbf{7 0}$ and the carboxylic acids $\mathbf{8 c}, \mathbf{8 d}, \mathbf{8 m}, \mathbf{8 n}, \mathbf{8 0}$ are reported in the literature [8-16] and are confirmed by matching the analytical data with the authentic compounds.

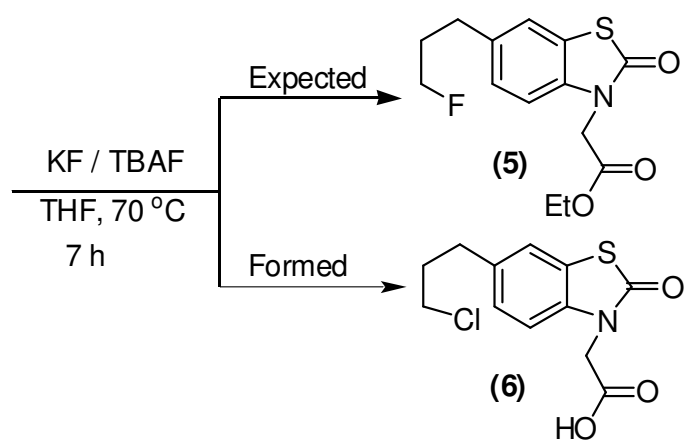

Scheme-I: Unexpected hydrolysis of ester derivative 
Further the reaction was tried on $p$-nitromethyl benzoate (7a) in different solvents (Table-2) and the solvent THF was found the best in terms of time and yield of the reaction. The hydrolysis reaction was performed on $p$-nitromethyl benzoate (7a) using other potassium halides under standardized conditions (Table-3). After $7 \mathrm{~h}$ the reaction with $\mathrm{KCl} / \mathrm{TBAF}$ and $\mathrm{KBr} / \mathrm{TBAF}$ was shown only $15-20 \%$ conversion. The prolonged reaction times upto $24 \mathrm{~h}$ did not increase more than a $5 \%$ further conversion. The reaction with KI/TBAF was still slow and showed only $8-10 \%$ conversion after $7 \mathrm{~h}$. The reaction was performed with TBAB, TBAI quaternary ammonium salts using potassium fluoride as alkali metal salt in aq. THF. But the reactions showed no formation of trace of corresponding carboxylic acids.

\begin{tabular}{ccc}
\multicolumn{3}{c}{ TABLE-2 } \\
& & \\
& & \\
& & \\
Solvent & Temperature $\left({ }^{\circ} \mathrm{C}\right)$ & Yield $(\%)$ \\
\hline Benzene & Reflux & 10 \\
MeCN & 80 & 25 \\
DCM & 40 & 20 \\
DMF & 100 & Trace \\
DMSO & 100 & Trace \\
EtOH & 70 & No reaction \\
THF & 70 & 93 \\
\hline
\end{tabular}

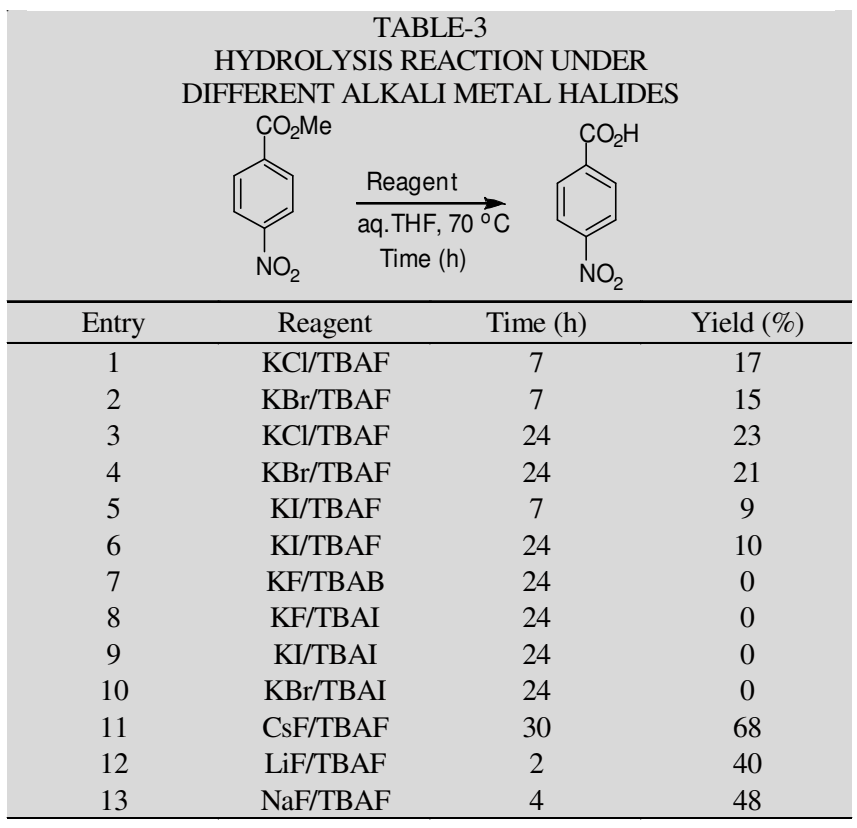

The combination of KI/TBAI, KBr/TBAB in THF was also tried but the reaction did not show any hydrolysis reaction. Further the hydrolysis reactions were tried with other alkali metal fluorides. The reaction with $\mathrm{CsF}$ was very slow and took $30 \mathrm{~h}$ to complete. The reaction with LiF was very fast and the ester was consumed on TLC within $2 \mathrm{~h}$ of time but the isolated yield was only $40 \%$ of acid along with $50 \%$ of the regenerated ester. The same reaction with $\mathrm{NaF}$ was comparatively slower than $\mathrm{LiF}$ which took almost $4 \mathrm{~h}$ to consume the ester and the isolated yield was around $48 \%$ along with $50 \%$ of the regenerated ester. Therefore, the reactivity and yields are found to be in the order of $\mathrm{LiF}>$ $\mathrm{NaF}>\mathrm{KF}>\mathrm{CsF}$ and $\mathrm{KF}>\mathrm{CsF}>\mathrm{NaF}>\mathrm{LiF}$, respectively. The mechanistic studies and the ester hydrolysis reactions with alkaline earth metal halides and transition metal salts are in progress.

\section{Conclusion}

A mild and versatile method for ester hydrolysis is disclosed. Under the optimized conditions, diverse esters have undergone the hydrolysis reactions to yield the corresponding carboxylic acids. The KF/TBAF combination is found as a best combination for ester hydrolysis reaction in terms of time, mildness and yield of the reaction. $\mathrm{LiF}$ and $\mathrm{NaF}$ were comparatively more reactive but the yield of the product was less compared to potassium fluoride. CsF needed prolonged times for ester hydrolysis. The acetate functionalities have also been undergone hydrolysis reaction to yield corresponding phenols. Under the reaction conditions, the chirality of the optically pure esters remain intact. The trial reactions with alkaline earth metal fluorides and transition metal fluorides are ongoing.

\section{ACKNOWLEDGEMENTS}

The authors are thankful to the financial assistances from DST with project No.SB/FT/CS-034/2012 (SERB, New Delhi, India) and UGC with project F.No.42-306/2013 (SR) (New Delhi, India).

\section{REFERENCES}

1. C. Hodl, K. Raunegger, R. Strommer, G.F. Ecker, O. Kunert, S. Sturm, C. Seger, E. Haslinger, R. Steiner, W.S.L. Strauss and H.-W. Schramm, J. Med. Chem., 52, 1268 (2009); https://doi.org/10.1021/jm800985z.

2. V. Theodorou, K. Skobridis, A.G. Tzakos and V. Ragoussis, Tetrahedron Lett., 48, 8230 (2007); https://doi.org/10.1016/i.tetlet.2007.09.074.

3. C.-G.Zhan, D.W.Landry and R.L. Ornstein, J.Am. Chem. Soc., 122, 1522 (2000); https://doi.org/10.1021/ja993311m.

4. K. Hori, Y. Ikenaga, K. Arata, T. Takahashi, K. Kasai, Y. Noguchi, M. Sumimoto and H. Yamamoto, Tetrahedron, 63, 1264 (2007); https://doi.org/10.1016/j.tet.2006.11.039.

5. Y. Izumi, Catal. Today, 33, 371 (1997); https://doi.org/10.1016/S0920-5861(96)00165-4.

6. Y. Koshikari, A. Sakakura and K. Ishihara, Org. Lett., 14, 3194 (2012); https://doi.org/10.1021/ol301290c.

7. M.L. James, B. Shen, C.L. Zavaleta, C.H. Nielsen, C. Mesangeau, P.K. Vuppala, C. Chan, B.A. Avery, J.A. Fishback, R.R. Matsumoto, S.S. Gambhir, C.R. McCurdy and F.T. Chin, J. Med. Chem., 55, 8272 (2012); https://doi.org/10.1021/jm300371c.

8. J.J. D'Amico and F.G. Bollinger, J. Heterocycl. Chem., 25, 1183 (1988); https://doi.org/10.1002/jhet.5570250427.

9. L. Srikanth, U. Naik and R. Jadhav, Int. J. Pharm. Biosci., 1, 260 (2010).

10. B.G. Raju, R. Ciabattl, S.I. Maffioli, U. Singh, G. Romano, E. Michelucci, S. Tiseni, G. Candiani, B. Kim and H. O’Dowd, Ramoplanin Derivatives Possessing Antibacterial Activity, US Patent 2006/0211603 A1 (2006).

11. Y. Yamamoto, Adv. Synth. Catal., 352, 478 (2010); https://doi.org/10.1002/adsc.200900836.

12. V.T. Perchyonok, S.J. Ryan, S.J. Langford, M.T. Hearn and K.L. Tuck, Synlett, 1233 (2008); https://doi.org/10.1055/s-2008-1072727.

13. A.J. Fugard, B.K. Thompson, A.M.Z. Slawin, J.E. Taylor and A.D. Smith, Org. Lett., 17, 5824 (2015); https://doi.org/10.1021/acs.orglett.5b02997.

14. C. Chaulet, C. Croix, J. Basset, M.-D. Pujol and M.-C. Viaus-Massuard, Synlett, 10, 1481 (2010); https://doi.org/10.1055/s-0029-1219918.

15. M.M. Johnson, J.M. Naidoo, M.A. Fernandes, E.M. Mmutlane, W.A.L. van Otterlo and C.B. de Koning, J. Org. Chem., 75, 8701 (2010); https://doi.org/10.1021/jo101873v.

16. S.-T. Huang, I.-J. Hsei and C. Chen, Bioorg. Med. Chem., 14, 6106 (2006); https://doi.org/10.1016/j.bmc.2006.05.007. 